\title{
Award-winning paper in 2012
}

Papers published in Bridge Engineering are eligible for awards from the Institution of Civil Engineers. Papers from any of the ICE journals can be nominated for several awards. In addition, each journal has awards dedicated to their specific subject area.

On Friday 18 October 2013, ICE president Barry Clarke presented an award to the following paper published in Bridge Engineering in 2012. The editorial panel nominated their best papers and an awards committee chaired by David Balmforth allocated the awards.

\section{John Henry Garood King Prize}

The John Henry Garood King Prize, awarded to the best paper on tunnels, soil mechanics or bridges, was awarded to Harvey (2012).

\section{Abstract}

Load-related damage to masonry bridges is relatively uncommon. The author is aware of only a small number of cases and nearly all of them are in structures carrying high railway loads. Current assessment tools do not deliver any indication of the failure mechanisms that actually occur. Those mechanisms are characterised by the progressive development of cracks in various positions. Recent observations have made it clear that: bridges with internal spandrel walls create complex stiffness issues; so-called spandrel cracks and apparent ring separation are different manifestations of the same issue; the construction of some small bridges is not as assumed but often includes internal spandrel walls. This paper describes the damage observed, the construction to which it is related and the mechanisms creating damage. No calculations of any form are offered. This paper merely provides a first step in identifying the cause of a problem and a potential approach to analysis. The discussion begins with stone masonry viaducts, progresses to brick viaducts and concludes with problems in small span bridges.

\section{REFERENCE}

Harvey B (2012) Stiffness and damage in masonry bridges.

Proceedings of the Institution of Civil Engineers - Bridge Engineering 165(3): 127-134, http://dx.doi.org/10.1680/ bren.11.00032.

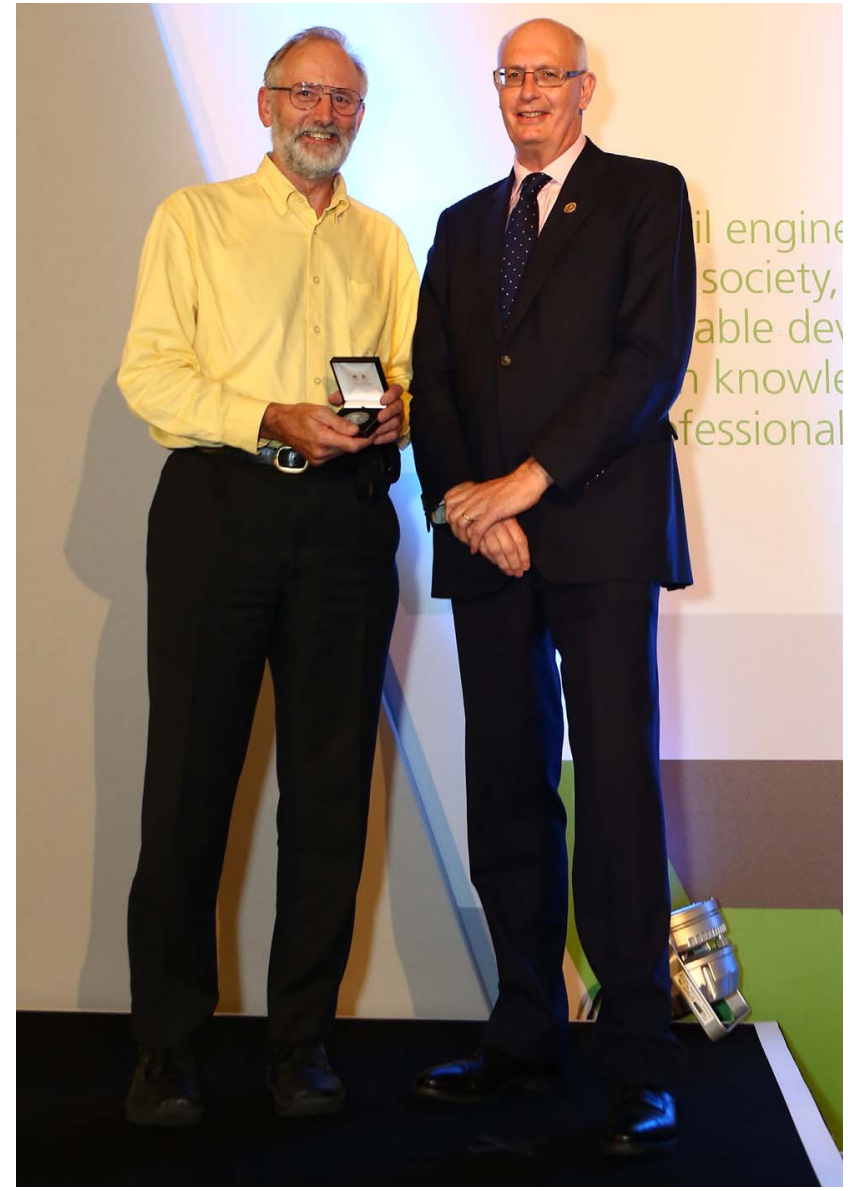

Bill Harvey, winner of the John Henry Garood King Prize, with ICE President Barry Clarke 